\title{
Putting Ecology to Use in the Community: An Analysis Needs Follow-up by Planning and Action, Part I: Analysis
}

\author{
Jacqui Laidler and Robert J. Gregory* \\ *School of Psychology Massey University, Palmerston North, New Zealand \\ Phone: $646350-5799$ ext. 2053 E-mail: R.J.Gregory@massey.ac.nz
}

KEYWORDS Community. Violence. Needs. Analysis

\begin{abstract}
Understanding the ecological relationship of child abuse and violence in society with the specific features of particular communities calls for analysis. Analysis, however, to be effective must be followed with planning and action. The community selected for study here has a median income lower than the national average and a high proportion of persons receiving an annual income of less than $\$ 20,000$. The community also has a higher number of persons without formal or tertiary qualifications, and of families caring for large numbers of dependant children, than is the case for New Zealand as a whole. Incidences of drug use, child hospitalization for injuries, and high-profile cases of domestic violence and murder are a reflection of the lack of optimal well-being. This study uses an ecological analysis in the face of such identified needs in Part I and reflects on the positive, strength-based actions taken and that could be taken by members of the community in their bid to provide intervention in Part II.
\end{abstract}

Infants and children are defenseless. When several are murdered in a community, the media take note and word travels to other communities quickly. One overwhelming response by all is to ask, why? Understanding what goes on in a community calls for an in-depth search for data, ideas, and facts, careful study and analysis of the information, and then, planning, followed ultimately by action to prevent such tragedies. The following story examines some information available about a New Zealand community where several children were murdered, and others were treated violently.

People yearn to belong; considering oneself a part of a network of relationships eventuates into forms of expression, intimacy, and feelings of usefulness (Heller, 1989). It is in this sense that an individual's sense of community (Dalton, 2001), including one's interdependence with others, perception of similarity, and meeting of needs, is rendered necessary for the psychological health of the individual. The goal of the community psychologist, with an ecological approach in mind, is to work to strengthen a sense of belonging to advance the well being of individuals, networks and groups in their social and physical environments.

A great diversity of meanings for community has been proposed. For example, Sarason (1974, cited in Dalton, 2001) defines community as a readily available, mutually supportive network of relationships on which one could depend (p.190). Gregory (1999) presents a further example, stating that a community comprises a group of people related through common values, a common location, communication patterns, and/or a relationship (p. 242). Accompanying this noted diversity (Heller, 1989), however, is the general agreement among community psychologists that definitions of community typically use two approaches, locality (geographical), or relational aspects (human interaction and social ties) (Dalton et al., 2001; Heller, 1989).

The locality approach, as described by Dalton et al. (2001), typically includes self-identifying via reference to one's geographic place, something Dalton suggests occurs when community members share a strong sense of community and loyalty to a specific place. A relational approach, in contrast, is defined by a sense of community and interpersonal relationships but is not limited by geography (Heller, 1989, cited in Dalton, 2001). For this study, the authors use a combination of the two approaches to define and explore a selected community.

The selected community is the town of Masterton, situated within the 605,491 hectares of central New Zealand that defines the Wairarapa. The Wairarapa is situated on the east coast of the North Island in parallel with 
Wellington, with the two regions being subdivided by the Rimutaka and Tararua Ranges. Masterton comprises 1485.5 hectares and is the most heavily populated urban area within the region, a total of 22,617 inhabitants at the time of the 2001 New Zealand Census of Population and Dwellings. In addition, two district areas within the Wairarapa are Carterton and Southern Wairarapa (consisting of the areas of Greytown, Featherston, and Martinborough) (www.stats.govt.nz, March 09, 2004).

The composition of Masterton is as follows: Of the 22,617 inhabitants, a total of $51.5 \%$ are females and $48.5 \%$ are males. $15.9 \%$ of the males and $15.8 \%$ of the females identify themselves as having Maori ethnicity, with a combined total of $16.3 \%$ persons, who permanently reside in Masterton, identify themselves as Maori. The proportion of Pacific peoples and of Asian peoples permanently residing in the community is $2.6 \%$ and $1.5 \%$ respectively. The median age of the inhabitants is 38.0 , with $15.5 \%$ aged over sixty-five years and above, and $23.4 \%$ aged fifteen years and below. (www.stats.govt.nz, March 09, 2004).

One-family households, averaging 2.5 people, comprise the largest type of household within the community, at $69 \%$. $26.4 \%$ of the inhabitants live in one-person households and less than 5\% live in households comprising two or more families. Couples with children make up $39.7 \%$ and couples with no children $41.7 \%$. The number of solo parent families in Masterton is $18.6 \%$. Slightly fewer Masterton inhabitants are married, separated, divorced or widowed than is the case for all of New Zealand as a whole (see www.stats.govt.nz), and $25.1 \%$ of people aged 15 years and over residing in the Masterton district, who have never been married, live with a partner. $71.2 \%$ of dwellings are owned with or without a mortgage, and the average weekly rent is $\$ 121.30 .7 \%$ of households have access to the Internet while $4.1 \%$ of households have no access to a telephone. The most common language after English spoken by members of Masterton is Maori at 4.6\% (www.stats.govt.nz, March 09, 2004).

The total median income for the area is $\$ 16,500$, compared with the national average of $\$ 18,500.58 .2 \%$ have an income of $\$ 20,000$ or less and $7.5 \%$ of the Masterton population has an income over $\$ 50,000$. $29.1 \%$ of community members aged fifteen years and above state they have a tertiary qualification and $34.9 \%$ of those of the relevant age state they have no formal qualifications. Masterton has a lower than the national average unemployment rate, at $7.1 \%$, and $38.4 \%$ of inhabitants are in receipt of a benefit. The most common occupation for Maori is agriculture and fishery workers, and for all of Masterton members it is service and sales workers (www.stats.govt.nz, March 09, 2004).

In comparison with New Zealand figures (refer www.stats.govt.nz) these averages demonstrate that Masterton is a community that is closely matched with national circumstances in terms of gender and the numbers of families with children. However it has higher than the national average of the following: the number of persons living alone, living with no children, earning under the national income average and earning under $\$ 20,000$, receiving a benefit, and having no access to a telephone. It also has a higher than the national average number of persons of Maori ethnicity, owning their own home and those who do not possess formal qualifications. Further differences in comparison to national circumstances are evident in the following lower than national average statistics as follows: the number of persons possessing tertiary qualifications, having access to the internet, of Asian or Pacific ethnicity, earning over $\$ 50,000$, living as solo parents, amount paid for rent, unemployment (www.stats.govt.nz, March 09, 2004).

The most substantial differences within these figures concern income, age, and education. The total average income in Masterton is low, and this applies for Maori, males, females, and the workforce as a whole. As rents are low however, it is possible disparities between national and regional income amounts are minimized by a reduced cost of living for the community, (perhaps also the high number of persons living on their own in Masterton are an indication of affordability, although it is possible these individuals allocate a high proportion of their income to rent/mortgage, and/or that they are in part comprised of the high numbers of elderly in the region (research shows elderly tend to live alone (Heenan, 1993)).

In education, the number of people who do not possess formal or tertiary qualifications is substantially greater than national averages. As Masterton unemployment is low compared with the whole of New Zealand, yet incomes remain 
low and benefit recipients are high within Masterton, it would appear that the low unemployment figures could in part be comprised of beneficiaries who are in part-time employment. This assumption can be further supported by the low levels of formal and tertiary qualifications (which tend to correlate with lower paid employment (Adams et al., 2000)) held by members of Masterton in comparison with national figures.

Finally, in terms of age, substantially higher numbers of elderly and also of persons under the age of fifteen years can be found in the community. As the region has a higher than average number of families without children, it would appear that the large numbers of dependant children are congregated within families of more than one child. This could present itself as a need area if particular families are representative of both a low-income family and an above average number of dependents. Exploring interventions targeted at these stated needs could be beneficial if further exploration confirmed that this type of need is evident in the community (provision of care for elderly, likely to be performed by female family/whanau members (Opie, 1992) and related stressors, could be a further factor in the equation to examine).

The significant statistics identified have indicated potential needs, all of which pertain to families. To view these issues in context, the use of an ecological level of analysis (Dalton, 2001) can be beneficial. Such an analysis views the individual as being embedded within environmental layers known as the microsystem (the immediate environment with which an individual engages, such as the family, and friendship networks), organizations (consisting of sets of microsystems, such as work teams within a department, and boards within a school), localities/communities (for example Masterton, consisting of community organizations and institutions), and the macrosystem (for example society, culture, and governmental policies) (Dalton, 2001).

The potential needs identified above can be assumed to place strain on the microsystem level of the family for community members, with low household incomes and a high number of dependant children for example, resulting in needs at the individual level, such as in areas of mental health or drug rehabilitation. At the organization and community levels one may be able to explore the degree of access to tertiary education that is provided and factors preventing the attainment of formal qualifications within the schooling system. One could also explore additional types of support that may be provided for families with dependents, such as the availability of afterschool and holiday programs and support services for elderly (the absence of such facilities can be an obstacle for parents, especially women, seeking paid employment (Baker, 2001)).

At the macrosystem level such things as cultural attitudes can be explored, for example the gendered expectation that it is the woman's primary responsibility to provide the care for the family's children and elderly. Statistics show a female's, rather than a male's, employment is likely to be correlated with the number and ages of children within the family (Baker, 2001). Also, consideration needs be given to the availability of government assistance, for example, the subsidy for childcare costs currently available only to families on a very low income rather than to all families in need (www.workandincome.govt.nz, March 10, 2004) and national/international economic factors such as the rise in living costs (Baker, 2001).

Such factors are just a few examples of the many variables that can be at play at any one time within the ecological levels of an individual's environment. The complex interactions between such variables possess interconnected, bi-directional relationships, in that the lives of individuals are strongly influenced by the factors associated with each ecological level, and in turn, individuals influence the factors residing at each level (Dalton, 2001). For this community, the statistics and potential need areas identified are clues of where to look in a bid to understand where discord in individual and family functioning may be originating.

What is evident for the community is that there does exist a lack of optimal functioning within the context of individual lives and individual family units. The region has a high rate of hospitalization for self-harm in young people, children are twice as likely to be hospitalized for burns and poisoning as children elsewhere in the country, $33 \%$ of the region's teenagers from the age of 14 to 17 meet the definition of heavier drinkers (more than five drinks during one drinking session) (www.nzherald.co.nz/ storydisplay, March 16, 2004), and alcohol use is also reported to be heavy among adults (http:/ /times-age.co.nz/weekly/drug, March 17, 2004). 
What is of even greater concern, however, are the statistics relating to violence in the community, which are disproportionately high compared with other regions (http://timesage.co.nz/news2002, March 16, 2004). Tragic high-profile cases of violence, such as the murders of two schoolgirls, O.J. and S.A. committed by their stepfather in December of 2001 (http://onenews.nzoom.com, March 16, 2004), the murder of schoolgirl K.G. by her mother s partner in August 2002 (http:// onenews.nzoom.com, March 16, 2004), and the January 2001 murder of two-year-old T.S. (http:/ /times-age.co.nz, March 16, 2004), are illustrative of such statistics and of the obvious lack of individual and family well-being. Two recent publications state that 449 reports of domestic violence were made to Wairarapa police during the year of 2003 (Romanes, 2004) and that there has been an increase in weapon use during domestic violent incidents (Wairarapa Midweek, February 3, 2004). It is clear the issue of domestic violence is of relevance.

Domestic violence, involving the abuse of a person who has an emotional bond with the abuser, is characterized by fear. The violence does not simply pertain to physical punishments, but includes verbal, emotional, sexual and mental abuse and consequently effects all parts of the victim's life; physical and mental health, emotional well-being, financial resources, employment, relationships and so on (www.womensrefuge.org.nz, March 16, 2004).

Although there is a tendency to acknowledge that males as well as women and children, are also victims of domestic violence, New Zealand statistics demonstrate that in 1998, 8\% of Protection Order applications were made by males compared with the $92 \%$ of applications made by females (www.womensrefuge.org.nz, March 16, 2004). It is clear that there is a strong likelihood that in the case of a domestic violent relationship, it is more likely that the male will be the perpetrator of the violence and the woman the target.

Domestic violence serves to form a pattern of power and control within the home, leaving the victims terrified for their lives and the lives of their children. These patterns of power over the individual, usually a woman, can be viewed as being backed up by systems within society (www.womensrefuge.org.nz, March 16, 2004).

For example, via frequent media portrayals of violence against women, which serve to desensitize viewers to the attacks and increases their tolerance (in a sense, rendering violence as normal). Further examples are the cultural attitudes that deem aggressiveness in the male as the norm and expectation (McLennan et al., 2000); and social structures that support the male's perspective as opposed to that held by females, which are fueled by the continued disproportionately higher levels of access that males have to positions of decision-making, power, and control of societies resources. For example, parliamentary representation of women in New Zealand is only $32 \%$ even though they comprise over $50 \%$ of the population. Surprisingly, New Zealand is considered liberal when it comes to gender equality; it is ranked sixth of 179 nations in terms of its relatively high level of female Parliamentary representation (Miller, 2001).

These stated factors are but a few of the many that exist within society that serve to compound the continued existence of violence within the home. The unfortunate reality is that many people, directly unaffected by violence in their own personal lives, have a part to play in keeping violence alive in the lives of others, simply via their unchallenged methods of participation in society at the organizational, locality and microsystem levels of society.

To illustrate, consider the following. Although it is commonly recognized that the Christmas season is a highly stressful time for families, in which the services of organizations such as women's refuge are expected to have increased numbers accessing them, it is not commonly recognized that this level of access is not as high as that which occurs during the rugby season months of March to September (www.womensrefuge.org.nz, March 16, 2004).

When any high profile rugby is played, our refuges have to deal with a significant rise in violence. Several areas noticed there was a particular increase when local favourites lost. While we acknowledge that the alcohol consumed by the rugby supporters can contribute to incidences of domestic violence, it is often used as an excuse. Despite being drunk or angry, violent men don't usually beat up or rape their friends when the team loses, they wait until they get home (www.womensrefuge.org.nz, March $16,2004)$.

The link between violence on the sports field 
and violence in the home is something that apparently has not been sufficiently recognized. With such a large cultural following of what can often be a violent game, the thousands who follow, play, support and generally engage in the aggressive behaviors surrounding rugby no doubt fail to think about how positively embracing and condoning violence in one context is confusing, to say the least, when such behavior is then condemned in another. This is culture at play; while all members of a community do not directly engage in the microsystem context of a violent family, all members do engage in the cultural element of the macrosystem.

Domestic violence is an international phenomenon, a national phenomenon, and as has been illustrated, it is certainly a phenomenon affecting the lives of many Masterton community members. Domestic violence is a symptom of discord and many interrelated factors. In this community, members evidently recognize this discord, as has been demonstrated by the approach taken by a local Violence-Free campaign. The campaign was sparked by the murders of schoolgirls $\mathrm{S}$. and $\mathrm{O}$. (mentioned above) (http://times-age.co.nz/news2002, 16 March, 2004) and represents a genuine strength and asset of the community. By implementing the four main principles of partnership, changing attitudes, improving well-being, and improving coordination, the combined efforts of over 24 community organizations (including the district councils; Stopping Violence Services; Safer and Healthy Community Council; Women's Refuge; Child, Youth and Family; Wairarapa Addiction Service; Whaiora Whanui; Strengthening Families, and more) continue to be used in a bid to intervene (http://www.swdc.govt.nz, March 09, 2004).

It is recognized by the Violence-Free campaign coordinator that violence is a symptom that needs to be addressed at both the individual and community level. The coordinator, J. S., states as individuals; don't accept violence, zero tolerance, look for help, and as community groups; realizing that no-one can make a difference on their own, by working co-operatively identifying the real causes and dealing with them (Wairarapa Midweek, February 03, 3004). In addition, the campaign can be further rendered as an asset when it is recognized that the organizers are working in collaboration with the community members, as illustrated by the stated importance of providing a forum for groups to come together and have an opportunity to discuss their issues, put forward at a recent campaign committee meeting (http://www.swdc.govt.nz, March 09, 2004).

Working in collaboration with community members is an important principle articulated by community psychologists, whereby the aim is to enable community members to contribute their knowledge and resources and to participate in the process of setting goals and making decisions (Dalton, 2001). Such participation is after all a characteristic of belonging, something all community members can claim a right to, and, as previously proposed, something all people yearn for (Heller, 1989). Building a sense of community, defined by McMillan and Chavis (1986, cited in Dalton 2001) as a feeling that members have of belonging, a feeling that members matter to one another and to the group, and a shared faith that members needs will be met through their commitment to be together (p193), is something community members ought to continue to strive towards; in doing so, the well-being of individuals and the community will be improved.

The statistics presented in this study have identified some key areas of need. Such factors can be used as a beginning point of access for analysis and intervention. Via the use of an ecological level of analysis one can consider these factors, in unison, with additional factors at each ecological level. It is in this sense that the individual is not viewed in isolation but within the context of her or his environment. Part II, to follow, will examine options for planning and action.

\section{REFERENCES}

Adams, P., Clark, J., Codd, J., O Neill, A., Openshaw, R., Ang, H.: Education and Society in Aotearoa New Zealand. Dunmore Press, Palmerston North, NZ (2000).

Baker, M.: Families and paid/unpaid work, Families: Labour andLove. pp. 147-175. Allen and Unwin, Crow's Nest, NSW, Australia (2001).

Brochure - Masterton District Census: Retrieved March 09, 2004, from http://www.stats.govt.nz/domino/\& Brochure+Masterton+District+Census $+2001+$ Area + dat (2001).

Common myths about family violence: Understanding violence against women and children. Retrieved 16 March, 2004, from http://www.womensrefuge.org.nz/ understand03.asp.

Dalton, J. H., Elias, M. J. \& Wandersman, A.: (2001). Community Psychology:Linking Individuals $\square$ with 
Communities. Wadsworth/Thomson Learning, Belmont, CA (2001).

Definitions and effects of violence: Understanding violence against women and children. Retrieved 16 March, 2004, from http://www.womensrefuge.org.nz/understand01.asp.

Gregory, R. J.: A conceptual framework or process model for community psychology. Journal of Social Sciences, 2, 4: 241-243 (1999).

Hann, S.: Media release: Rugby season is a nightmare for Women's Refuge. Retrieved 16 March, 2004, from http:/ /www.womensrefuge.org.nz/news03.asp (2002).

Heenan, B.: Older New Zealanders: Population Patterns and Trends. pp. 29-54. In: New Zealand's Ageing Society. Peggy G. Koopman-Boyden (Ed.). Wellington (1993).

Heller, K.: The Return to Community. American Journal of Community Psychology, 17(1): 1-15 (1989).

McLennan, G., Ryan, A. \& Spoonley, P.: Exploring Society: Sociology for New Zealand Students. Pearson Education New Zealand Limited, Auckland (2000).

Minutes of the Wairarapa Violence Free Project Implementation Committee Meeting, held 02 September 2003. Retrieved 09 March, 2004 from, http://www.swdc.govt.nz.

Nzoom.com, One News: Call for change after deaths. Retrieved March 16, 2004, from http://onenews.nzoom.com/ onenews detail/0m1227,235426-1-7,00.html (2003).

Nzoom.com, One News: CYF admits errors in child's death. (2003). Retrieved March 16, 2004, from http:// onenews.nzoom.com/onenews detail/0,1227,243614-17,00.html

Official Home Page of Work and Income New Zealand, (2004). Retrieved March 18, 2004, from http:// www.workandincome.govt.nz.

Opie, A.: The common round, the daily task : Caring in everyday life. There's Nobody There: Community Care of Confused Older People, Pp. 85-121. Oxford University Press, Auckland (1992).

Romanes, B.: OurChildren: Theirhealth: $\square$ Tatoutamariki $\square$ toratou puawai ora. A Wairarapa District Health Board Publication: Kitchen Sims Communications, Wairarapa DHB (2004).

The New Zealand Herald: Survey damns Wairarapa home violence. Retrieved March 16, 2004, from http:// www.nzherald.co.nz/storydisplay (2004).

Wairarapa Times-Age: Anti-violence has power to shock. Retrieved March 16, 2004, from http://times-age.co.nz/ news2002/020427c.html (2002).

Wairarapa Midweek: Owning violence. Retrieved 03 February 2004 from the Wairarapa midweek newspaper (2004). 